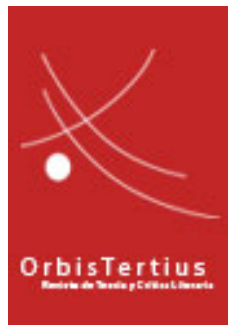

Orbis Tertius, vol. XXIII, $n^{\circ}$ 27, e068, junio 2018. ISSN 1851-7811

Universidad Nacional de La Plata

Facultad de Humanidades y Ciencias de la Educación

Centro de Estudios de Teoría y Crítica Literaria

\title{
Sangre, luto y horror en tiempos de Rosas: figuras del terror y el caos en 'Tablas de sangre' de Rivera Indarte
}

\section{Leandro Ezequiel Simari *}

* Universidad de Buenos Aires, Argentina.

Cita sugerida: Simari, L. E. (2018). Sangre, luto y horror en tiempos de Rosas: figuras del terror y el caos en 'Tablas de sangre' de Rivera Indarte. Orbis Tertius, 23 (27), e068. https://doi.org/10.24215/18517811e068 


\title{
Sangre, luto y horror en tiempos de Rosas: figuras del terror y el caos en 'Tablas de sangre' de Rivera Indarte
}

\author{
Leandro Ezequiel Simari \\ Universidad de Buenos Aires, Argentina
}

\begin{abstract}
Resumen:
El siguiente trabajo analiza los modos en que "Tablas de sangre"de José Rivera Indarte establece sus mecanismos de representación y propaganda contra el régimen de Juan Manuel de Rosas a partir de la exacerbación y acumulación de tópicos y estrategias de amplia difusión en la prensa y la literatura del antirrosismo, sobre los que ofrece una versión tan singular como radical. En un texto que registra en varios niveles las tensiones entre lo sistemático y lo desmesurado, lo calculado y lo incalculable, las figuras del caos y el terror como ejes del sistema despótico de poder desplegado por Rosas se transforman en pilares de una denuncia que lleva hasta las últimas consecuencias los alcances y posibilidades de la escritura facciosa.
\end{abstract}

PALABRAS CLAVE: literatura argentina - Rivera Indarte - Rosas - terror .

\section{Abstract:}

This paper analyzes the ways in which Jose Rivera Indarte's"Tablas de sangre"establishescertain mechanisms of representation and propaganda against the regime of Juan Manuel de Rosasthrough the exacerbation and accumulation of topics and strategies widely disseminated in the press and the literature of the "antirrosismo" movement. This uniqueand radical text registers, on several levels, the tensions between the systematic and the excessive, the calculated and the incalculable. Moreover,the figures of chaos and terror, the axes of the despotic system of power deployed by Rosas, are transformed into the pillars of adenouncementthat leadsthe scope and possibilities of factious writing to its ultimate consequences.

KEYWORDS: argentine literature - Rivera Indarte - Juan Manuel de Rosas-terror .

El 13 de abril de 1835, a dos años de haber culminado su primer mandato, Juan Manuel de Rosas retorna al gobierno de la provincia de Buenos Aires, investido esta vez con la suma del poder público, e inaugura su período de mayor y más duradera influencia sobre la vida política, social y cultural del Río de la Plata. Según relata Adolfo Saldías (1978: 9), las manifestaciones de adhesión al nuevo régimen, esparcidas en días sucesivos, tuvieron por corolario una velada teatral que un joven poeta federal clausuró entonando su

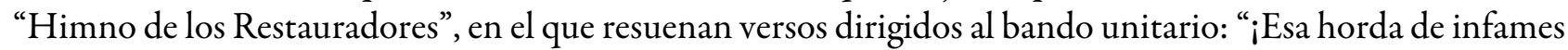
¿qué quiere? / sangre y luto pretende, iqué horror! / empañar nuestras nobles hazañas / y cubrirnos de eterno baldón!".

Su autor es José Rivera Indarte, el mismo que, cuatro años después, ya exiliado en Montevideo, y luego de una breve colaboración en periódicos de la prensa oficialista ${ }^{1}$, orientaría su prédica en exacto sentido contrario. El antecedente espurio de un pasado federal no le impidió, en efecto, ocupar, desde las páginas del diario El Nacional, de cuya redacción se hizo cargo en julio de 1839, un lugar en las filas de los más vigorosos detractores del rosismo. Más que a las poesías que su amigo Bartolomé Mitre compiló y prologó en 1853, a siete años de su muerte, y más que a su producción temprana, su nombre quedará asociado a esa segunda faceta de su escritura, en la que el héroe se trasmutó en tirano y la infamia declamada cambió de partido.

En cualquier caso, el primer proyecto de historizar la literatura argentina habría de confirmar para Rivera Indarte el lugar desplazado y marginal que ya le había sido asignado por sus contemporáneos. Si Esteban Echeverría, en su "Ojeada retrospectiva", lo incluye al paso en la nómina de escritores que, en tanto "no profesan nuestras doctrinas” (2007: 138), sólo se emparentan con los miembros de la llamada Asociación 
de Mayo ${ }^{2}$ por motivos de coyuntura política, el ingreso de Rivera Indarte entre Los proscriptos que Ricardo Rojas estudia tendrá lugar únicamente, como el propio autor admite, "con muchas reservas" (1948: 483).

Excepción hecha de algún elogio mínimo y parcial, la opinión de Rojas es casi por completo lapidaria: "su obra es, en sus versos, testimonio del escaso gusto de su época, y en su prosa, documento de esa airada elocuencia del rencor que asumió a veces la propaganda de los emigrados" (1948: 484). Y, para redondear su punto de vista, en un ejemplo del doble juicio, literario y biográfico, que le es habitual, terminará confinándolo al octavo lugar en una jerarquía de escritores de la época porque, en cuanto a la "unidad moral" de su vida y a la "perfección estética" de su obra, "siete varones de la proscripción lo superaron" (493).

Por su parte, la alusión al paso de Echeverría a Rivera Indarte entre los escritores contemporáneos se recorta sobre el trasfondo de una mutua antipatía que, hacia 1844 , devino en polémica abierta. Aquel año ambos coincidieron en las celebraciones montevideanas del 25 de mayo, organizadas por Andrés Lamas en el teatro del Comercio bajo el auspicio del Instituto Histórico-Geográfico Nacional del Uruguay que él mismo presidía. Una instancia de la celebración consistió en la lectura de composiciones poéticas alusivas, que la concurrencia recibió con distintos grados de aprobación. Participaron de la velada Francisco Acuña de Figueroa, Bartolomé Mitre, José María Cantilo, Luis Domínguez y Alejandro Magariños, además de Echeverría y Rivera Indarte. El modo en que este último reseñe las incidencias del evento, en una crónica para El Nacional, será la circunstancia que dispare una escalada de agresiones verbales, entramada en textos privados y públicos, no sólo dirigida a dirimir la disputa puntual, sino orientada, además, a liquidar viejas inquinas. En efecto, la discusión deriva de las recriminaciones iniciales de Echeverría a Rivera Indartepor no haber remarcado la aprobación que su poesía habría recibido del público (como sí se ocupa de hacer en el caso de Domínguez) ${ }^{3}$, a un prolongado duelo de egos en el que, sin embarazo, el primero no escatima elogios a sí mismo, mientras que el segundo asegura estar ya a la altura de su contendiente como poeta, a pesar de ser casi una década más joven, y tener el talento para, con el paso de otra década, "dejarlo si quiero un par de cuadras a mi retaguardia" (Rivera Indarte 1941a: 172).

El derrotero de la polémica pone de manifiesto hasta qué punto la lapidaria opinión de Echeverría sobre Rivera Indarte se emparenta con la de sus detractores contemporáneos y la de sus poco entusiastas críticos futuros. Cuando cundan las mutuas acusaciones de falta de originalidad, Echeverría dirá a su rival:

¿[q]ué doctrina social ha formulado usted en su apostolado de cinco años en El Nacional; qué idea nueva ha emitido, qué importación inteligente nos ha inoculado, qué poesía original nos ha revelado, qué intuición de su genio nos ha embutido?... ¡Apostolado para el pueblo, dice usted! Apostolado de sangre, de difamación, de inmundicia (1941a: 181)

Cuando, en cambio, la discusión circule por el territorio de la respectiva labor en el marco de la lucha contra Rosas, Echeverría jugará una carta que Rivera Indarte no puede no haber previsto: la referencia a su pasado en el rosismo. Más aun, no se conformará únicamente con afirmar su pertenencia a la Mazorca ${ }^{4}$, o con recuperar las primeras inclinaciones de su literatura de propaganda ${ }^{5}$, sino que, además, aludirá al confuso episodio que parece haber marcado el quiebre rotundo de Rivera Indarte con el régimen: su estadía en prisión. ${ }^{6}$

Así, tempranamente, la figura de Rivera Indarte comienza a cristalizarse en pocos y simplificadores rasgos que su muerte, los vaivenes políticos, la adscripción facciosa de quien los esgrima y las relecturas de varias décadas posteriores dejarán casi inmutables: un escritor virulento, una escritura infame e infamante, un hombre de dudosa moral, convicciones mudables, trayectoria zigzagueante. Entre el descrédito a su persona y a su oficio, sancionado desde una perspectiva que entremezcla juicios moralistas, ideológicos y de purismo estético (sin olvidar miserables rencillas personales), ya no será releído por fuera de los parámetros que demarcan esas primeras aproximaciones. Ni los elogios que Mitre le depara en la biografía que escribe como introducción a su antología poética lo salvarán de convertirse, a los ojos de los estudios literarios, en una página menor de la tradición argentina, una firma eclipsada a perpetuidad por los nombres mayores del romanticismo rioplatense. Y, sin embargo, si "su pluma solo corrió a impulsos de las pasiones vergonzantes de la época” (Saldías 1978: 333), si su escritura supura sangre e inmundicia a fuerza de exacerbar las estrategias 
difamatorias que en la producción de los románticos más eminentes aparecen atenuadas, dispersas, sugeridas, dichas desde el anonimato e incluso autocensuradas, entonces excluir a Rivera Indarte del plano de análisis no equivale a descartar del canon literario nacional una rareza radical, una absoluta anomalía. De lo que se trata, en todo caso, es de amortiguar los ecos de una nota altisonante que deja percibir, reunidos y acentuados, algunos de los aspectos determinantes para la escritura y los escritores en épocas de Rosas. A un tiempo, se descarta, como sugiere Nicolás Lucero, "la diatriba por no-literaria (no decorosa) [y] se cercena una perspectiva de comprensión de la escritura del período rosista” (1992: 9), para estabilizar los orígenes de la literatura argentina en un corpus más asible y asequible.

Punta de lanza en una batalla propagandística sin cuartel, el verdadero arsenal de imprecaciones, denuncias y figuras injuriantes que Rivera Indarte trama en sus textos es, a la vez, fruto y muestrario del despliegue de violencia discursiva que dio marco a casi toda la producción del romanticismo rioplantense, incluso en sus piezas más celebradas. Pero, además, su literatura facciosa guarda todavía otro punto de interés, casi un privilegiado núcleo de significación que se deriva de lo que, durante su vida e incluso en las primeras relecturas posteriores a su muerte, se consideró siempre un estigma: su condición de traidor. Porque es en las torsiones que registra la escritura del converso donde se delata un rasgo crucial para comprender la producción literaria de la época: la reversibilidad de las agresiones simbólicas, la pugna sostenida por el uso de imágenes, términos y figuras cuyas cargas semánticas e implicaciones políticas redefinen sus alcances, sus referentes y sus contextos de aplicación en función de los actores que las emplean. "[L]ucha simbólica" (Kohan 2005: 189), lucha por el sentido (Schvartzman1996), “disputa en torno a las palabras y sus usos” (Ansolabehere 2012: 240): los estudios críticos sobre la literatura del período enfatizan la guerra discursiva que los románticos argentinos establecieron con el rosismo para validar su derecho a servirse con exclusividad de cierta zona del imaginario vigente. En esta coyuntura, apostrofar de bárbaro o de salvaje, sea quien sea el enunciador y el destinatario de la injuria,implica una agresión por partida doble: se trata de (des)calificar al otro y, en simultáneo, negarle el uso de la palabra, el uso de ciertas palabras, desautorizando el discurso que las encierra y el imaginario que lo sostiene. Aunque no el único hombre público en cruzarse de bando, Rivera Indarte resulta, en este sentido, paradójicamente ejemplar; porque exhibe, en su recorrido individual, la reversibilidad de esas armas retóricas de doble filo que tan pronto un joven poeta federal pudo esgrimir contra los detractores de Rosas como un adulto partidario de la oposición emplear contra el mismo bando rosista.

En efecto, cuando centre su actividad propagandística en las páginas de El Nacional, serán las mismas figuras de la sangre, el luto y el horror,que en su poema de juventud se vinculaban con la infamia que investía a los salvajes unitarios, las herramientas fundamentales de un discurso dirigido en exacto sentido contrario. Si la literatura canónica del antirrosismo redunda en figuras asociadas a estos tres términos, Rivera Indarteno sólo destaca por llevarlas al límite de su expresividad cualitativa y de su proliferación cuantitativa, sino también por haber demostrado su eficacia para ser puestas al servicio de cualquiera de los bandos en pugna.

Sangre, luto y horror: los tres términos resuenan en todos los escritos de Rivera Indarte, se repiten y resignifican para acusar a Rosas de atrocidades diversas y dimensionar los efectos devastadores de su gobierno. Más aún, en la versión del rosismo que Rivera Indarte construye, estos tres elementos no sólo se recubrende densidad simbólica en el plano retórico: también destacan como componentes centrales del sistema ilegítimo de gobierno que se atribuye a Rosas, engranajes principales dentro de su maquinaria de poder que deben ser comprendidos y evidenciados. Esa parece ser la misión principal que Rivera Indarte encomienda a uno de los apéndices incluidos en su libro de 1843, Rosas y sus opositores, titulado, de manera sugestiva, "Tablas de sangre".

\section{La desmesura y el cálculo: “Tablas de sangre” y el sistema del caos}

Hemos formado, pues, tablas alfabéticas de la sangre derramada por órden de Rosas, comprendiendo en ellas solo víctimas muertas a hierro óá fuego, cuyos sacrificios constan de documentos oficiales ó de relación dada por testigos dignos de fé. 
Muchísimas serán las que omitiremos y que no hemos podido averiguar en la incomunicación en que estamos con el interior de Buenos Aires y las otras Provincias (Rivera Indarte 1853: 274).

Así anticipa Rivera Indarte, al final de Rosas y sus opositores, el propósito de "Tablas de sangre". Aunque con la irrupción esporádica de pasajes argumentativos o adjetivaciones fuera de tono ${ }^{7}$, el texto se estructura, en efecto, en entradas alfabéticamente ordenadas que, "a la manera de un implacable y gélido diccionario" (Area 2006: 199), pretenden registrar, con una retórica de hipotética neutralidad, todas las violencias del rosismo desde 1829 hasta 1843 . El calculado enmascaramiento de la función propagandística detrás de una supuesta precisión estadística e histórica terminará por diseñar un posicionamiento ambivalente en relación con las polémicas de la época. Hacia el interior del texto, en efecto, las estrategias retóricas que Rivera Indarte prioriza (el tono predominantemente neutro, la exposición sumaria de hechos sin marcas fuertes de subjetividad, la apelación a la fecha, a la estadística, a la cita de otras voces que testimonien los horrores vistos o padecidos) deniegan para "Tablas de sangre" una veta polémica, lo ubican más allá del debate y colocan sus denuncias por fuera de la discusión. A diferencia del resto del volumen que integra, el texto no explica, no opina, no argumenta: simplemente expone una verdad que se postula como empírica y absoluta, no construida y parcial. Hacia el exterior, sin embargo, "Tablas de sangre" y, muy especialmente, sus versiones preliminares publicadas en El Nacional bajo el título de "Efemérides de los degüellos y matanzas de Rosas", desencadenarán una encendida respuesta por parte de la prensa rosista, que atacará de lleno la principal estrategia del texto: su presunción de objetividad. En particular, Nicolás Mariño, desde la dirección de La Gaceta Mercantil, encabezará el contrataque en al menos dos direcciones. Por una parte, se ocupará de la desmentida, punto por punto, de muchos de los crímenes atribuidos al régimen ${ }^{8}$. Por otra parte, atacará con énfasis la autoridad moral de Rivera Indarte como escritor, la exactitud de sus datos y la objetividad de su perspectiva. Y, si en ocasiones elige combatirlo con severidad, reputando su mirada de tendenciosa y falaz y ocupándose de contraponer fechas, nombres y datos a las fechas, nombres y datos que las "Efemérides" esgrimen, en más de una ocasión la estrategia de Mariño consistirá en subestimar sus acusaciones por adolecer del mismo rasgo que detectarían todas las miradas críticas sobre su producción: la desmesura.

Para Mariño, la desmesura en las "Efemérides" que luego pasarán a integrar "Tablas desangre"es una de sus facetas censurables, prueba de su parcialidad, motivo de descrédito para las acusaciones que transportan y para el nombre de su autor. Desde su perspectiva, tan sesgada como la del propio Rivera Indarte, la matriz de esa desmesura se encuentra sobre todo en la cantidad de muertes atribuidas al régimen rosista: cifras infladas de manera tendenciosa que, en la escasamente poblada Argentina, se emparentan con las que arrojaban los años más cruentos de la Revolución Francesa y que, a la vez, parecían sugerir que entre 1829 y 1842 toda muerte por la violencia en suelo argentino encontraba una responsabilidad primera o última en la figura de Rosas. Despojada de una orientación facciosa que la obligue a emitir juicios taxativos, una relectura de "Tablas de sangre" podría validar, sino las conclusiones, al menos el punto de partida de dicho razonamiento. Porque si hay algo en "Tablas de sangre" que remite a la tan mentada desmesura que se atribuye a su autor es su faceta cuantitativa: su pretensión de cubrir con exhaustividad los crímenes del rosismo durante más de una década hace que cada entrada acumule y multiplique fusilamientos, degüellos, decapitaciones, torturas, mutilaciones, batallas y aberraciones por el estilo,

Contra lo que podría suponerse a priori, que los modos de enunciación del texto sean austeros, regulados por la rigidez del orden alfabético ${ }^{9}$ y la entonación neutra, no hace sino potenciar el efecto de esa desmesura cuantitativa: la lectura se desliza sin contratiempos y, en su avance precipitado, suma defunciones y atrocidades de una en una o de cientos en cientos. En ese cruce, en esa tensión entre mesura y desmesura, se encuentra no sólo el principio constructivo de "Tablas de sangre", sino también la matriz de su estrategia propagandística, cuya principal orientación consiste en recrudecer la imagen de la violencia rosista, acumular 
y magnificar sus crímenes, sumergir al lector en una vertiginosa sucesión de aberraciones denunciadas con crudeza, simpleza y brevedad.

La organización de ese material desbordante en entradas ordenadas alfabéticamente, por otra parte, desarticula la cronología de los hechos y complejiza su incrustación en una linealidad histórica de causas y efectos. De este modo, se encadenan series de entradas que provocan avances y retrocesos en el tiempo o que, en otros casos, siquiera resultan datadas:

Jaramillo, vecino de Mendoza: es asesinado en dicha ciudad el 19 de setiembre de 1829.V. Aldao. [...]

Jourdan, vasco francés; es asesinado con dos más de su nación el 4 de febrero de 1841.

Juárez (Solano); uno de los individuos que fusiló Rozas con los Reinafés después de dos años de una horrible prisión, por cómplices en el asesinato del general Quiroga, en que Rozas fue juez y ejecutor.

Junio de 1831. El tirano Rozas se aboca las causas criminales pendientes ante los jueces de Buenos Aires y hace fusilar en San José de Flores a 11 individuos (Rivera Indarte 1853: 296).

Los hechos denunciados, entonces, pasan a superponerse, en el efecto acumulativo que acompaña la lectura, en una suerte de tiempo sin tiempo: el tiempo de la infamia del rosismo. La ausencia de una narración que enlace episodios conectados por la causalidad y las referencias nulas a toda circunstancia que, sin justificar, pudiera contextualizar los episodios referidos en un clima generalizado de agitación y violencia, potencian la pátina de sadismo irrefrenable que parece recubrir todos los actos y decisiones del tirano y sus seguidores.

Además, gracias a un criterio lábil en su elección, las entradas de "Tablas de sangre" no sólo nombrarán víctimas, sino también victimarios, lugares, meses del año, entre otras referencias todavía más asistemáticas. Más que por simplemente engrosar la cantidad de entradas, ese rasgo redobla el carácter acumulativo del texto por otro motivo: la repetición. El mismo episodio se reitera y distribuye, de este modo, en entradas diferentes que lo aluden de manera distinta, propiciando un efecto multiplicador. El asesinato de Quiroga, por caso, se refiere, además de en la entrada ya citada sobre Solano Juárez, en la entrada que lleva su nombre, en la entrada destinada a Barranca Yaco y en la que se dedica a su secretario, Santos Ortiz. Quiroga y sus acompañantes mueren varias veces a lo largo de "Tablas de sangre".

La austeridad dominante en su enunciación, la reiteración de ciertos términos y frases que adquieren el estatuto de fórmulas y la disposición alfabética de un material que, en línea con otras zonas de la producción del mismo autor, podría tender al desborde y la inflamación retórica, tensan así buena parte del potencial propagandístico y faccioso de "Tablas de sangre" sobre un encadenamiento de paradojas. En una primera instancia, las modalidades de enunciación rígidas, estructuradas, ordenadas, a través de las cuales se denuncian los crímenes del régimen de Rosas contribuyen, en su mesura, a incrementar la desmesura cuantitativa de las denuncias efectuadas, a remarcar lo que la violencia del rosismo tiene de desmesurada e inconmensurable. No obstante, cuando "Tablas de sangre" ya hace prever que el daño que Rosas hace al país resulta incalculable en el más estricto sentido de la palabra, Rivera Indarte introduce una nueva torsión bajo la forma de un prolijo y prolijamente falaz ${ }^{10}$ balance que pone cifras definitivas al texto y a los actos bárbaros que denuncia: “4 ENVENENADOS, 3.765 DEGOLLADOS, 1393 FUSILADOS, 722 ASESINADOS, 14920 MUERTOS EN ACCIONES DE ARMAS” (1853: 317).

De este modo, se diría que "Tablas de sangre"combina dos estrategias de denuncia opuestas y complementarias: primero, la vertiginosa e inconmensurable acumulación de crímenes; después, la precisión de la estadística y el cálculo, que clarifica en números lo que el texto hace proliferar hasta la disipación.

Pero la tensión entre orden y desborde, entre cálculo y desmesura, no sólo constituye un rasgo central en los modos de enunciación del texto, no sólo es uno de los principios rectores de su estrategia propagandística: también forma parte de la tesis implícita que "Tablas de sangre” deja leer, atravesada y sugerida en su organización de diccionario. Porque la misma tensión que se registra en la configuración del texto se presiente en el sistema de gobierno que éste atribuye a Rosas: un sistema que funda su estrategia de dominación sobre una calculada proliferación del caos, sobre una planificada transgresión de todo límite. Si "Tablas de sangre" es la metódica condensación y exposición, a través de un sistema definido, de una enorme cantidad de datos 
sobre la barbarie, el poder de Rosas parece fundado sobre la instauración de un régimen que, anulando el orden establecido y reemplazándolo por la voluntad del tirano como única fuente de autoridad, consigue instaurar una sistemática difusión del desorden y la violencia. Con otro desarrollo y en el marco de un texto de alcances y pretensiones por completo diferentes, una idea similar será central para Sarmiento: "y lo que en él [en Facundo Quiroga] era sólo instinto, iniciación, tendencia, convirtióse en Rosas en sistema, efecto y fin" (2006: 13). Rosas es el caos, la brutalidad, la barbarie hechos sistema: el salvaje entronizado en la ciudad. La desmesurada proliferación de violencia no oculta, a la mirada analítica de Sarmiento y Rivera Indarte, el plan calculado que le da sustento.

\section{El terror político según "Tablas de sangre”: sangre, luto y horror}

Rosas como director y eje de un sistema que funda su poderío y su eficacia en la transgresión de los límites impuestos por los valores de la civilización, en la destrucción de las instituciones que sustentan la vida civilizada, y en su reemplazo por una calculada y metódica proliferación de la violencia y el caos: esa tesis, que en "Tablas de sangre" opera como un sobre entendido, se explicita en el resto de los textos reunidos en Rosas y sus opositores. Así, por ejemplo, se lee en el apéndice más violento y panfletario de los que componen el libro, titulado "Es acción santa matara Rosas": "el despotismo de Rosas no es ni una costumbre, ni una tradición, ni una constitución de Buenos Aires, sino la violación de los usos, de las tradiciones de las leyes más sagradas de esa tierra infeliz" (Rivera Indarte 1853: 323). Y, más adelante, a través de una cita de Lefebvre de Becour: "Rosas ha substituido su persona a todas las instituciones y a todos los sentimientos, ha sometido toda una población al culto de su propio retrato"(328).

En la representación de Rivera Indarte, el régimen de Rosas encarna el despotismo; en él "uno solo, sin ley y sin regla, conduce todo por su voluntad y capricho" (Montesquieu 2007: 36), anclando su poder soberano en el ejercicio del terror como mecanismo de sometimiento para neutralizar la iniciativa de los hombres, devenidos en "esclavos" (Montesquieu 2007: 55). La segunda entrada de "Tablas de sangre" demostrará hasta qué punto la perspectiva de Rivera Indarte se ampara en la filosofía política de Montesquieu:

Abril. El 13 de este mes del año 1835, se apodera Rozas, por el terror, del Gobierno de Buenos Aires, conculca las leyes divinas y humanas, quita vidas y haciendas y obliga a los habitantes de Buenos Aires a celebrar su ominoso advenimiento (1853: 276).

Todas las denuncias acumuladas en "Tablas de sangre" pretenden ser constataciones de esta alusión inicial: Rosas funda su poder despótico en el ejercicio del terror. Aunque su nombre aparezca mencionado en las argumentaciones generosas en citas de "Es acción santa matar a Rosas", Montesquieu y su filosofía resuenan en la escritura de Rivera Indarte sobre todo a partir del uso de ese término. Aun cuando la filosofía política ya había recurrido a él con anterioridad, Montesquieu otorga al concepto de terror político un relieve específico. En palabras de Corey Robin,

u]nlike Hobbesian fear, Montesquieu's terror was not the product of law, institutions, education, or even elites. It arose instead from a lone despot's use of lawless violence, which decimated institutions and elites and dispensed with education (2004: 29).

Sin embargo, a partir de los acontecimientos que, entre 1793 y 1794, cambiaron el rumbo de la Revolución Francesa, la noción de terror se reviste de un nuevo matiz. Desde entonces, guarda también la marca indeleble de la violencia política sostenida y generalizada del llamado Terror revolucionario, una denominación tempranamente adoptada por el discurso historiográfico. En el imaginario de Rivera Indarte ambas inflexiones parecen articularse.

Caos sin ley y uso político del terror: para Rivera Indarte, son estos los principales ejes de la maquinaria de poder que despliega Rosas. Ambos operan unidos, se retroalimentan: el fin de la institucionalidad, las reglas y los límites que "Tablas de sangre" denuncia es la condición de posibilidad para la multiplicación de zonas 
promiscuas en las que se tergiversan lo legal y lo ilegal, lo religioso y lo profano, la vida y la muerte, lo humano y lo animal, lo público y lo privado; al mismo tiempo, sobre esas indistinciones caóticas se vertebra el terror que promueve Rosas, puesto que nada ni nadie queda a resguardo de su poder soberano. Al mismo tiempo, la entronización del déspota a través del terror habilita, sin resistencias, su transgresión continua de los límites y anula toda posibilidad de su regeneración.

Si caos y terror son, a la vez, artífices y resultantes del poder soberano de Rosas y su perpetua trasgresión de los límites, "Tablas de sangre" se ocupará de poner en evidencia sus efectos y alcances justo allí donde su confluencia resulta más visible e insistente: en el cuerpo del enemigo. Abolir toda garantía del individuo, traspasar la barrera que demarca su autonomía y su integridad física, apropiarse de su materialidad biológica, torturarlo, marcarlo, empujarlo a la destrucción: el caos y el terror se ejercen en, con, a través del cuerpo del enemigo, devenido en propiedad del déspota. La violencia física sobre él aplicada cumple, de hecho, un doble rol: a la vez castigo directo y advertencia, pune la rebeldía política de un individuo y hace que su cuerpo sea símbolo, mensaje o amenaza. Sólo en esos términos puede entenderse el énfasis en denunciar los modos en que Rosas hace de los tormentos infringidos a sus enemigos un espectáculo: "cabezas de víctimas [...] puestas en el mercado público adornadas con cintas celestes” (1853: 276), ejecuciones en las plazas, degüellos en las calles y una descomedida cantidad de cadáveres insepultos que sugieren la imagen de una Buenos Aires mortuoria y putrefacta.

Sin embargo, la lógica de la violencia rosista sobre los cuerpos alcanza, según "Tablas de sangre”, un más allá de la tortura y muerte de los vivos: también se utiliza, como amenaza a los vivos, sobre el cuerpo de los muertos. Así, por ejemplo, las mutilaciones sufridas por Marco Avellaneda tienen lugar luego de su ejecución, y transportan únicamente una carga simbólica dirigida al resto de la población: "le abrieron el pecho, lo castraron y las partes pudendas con la grasa la colgaron de un árbol y la cabeza la clavaron en un palo en medio de la plaza de Tucumán" (1853: 288). Asentado sobre la transgresión de los límites, el poder soberano de Rosas arrastra el cuerpo violentado del enemigo hacia esa zona de indistinción "entre la vida y la muerte" (Agamben 2006: 201) en la que se convierte en vida desprotegida frente a las arbitrariedades del tirano. En ella, el cuerpo no sólo puede perder su condición de viviente, sino además su forma y su condición de humano:

el coronel don Manuel Rico [...] fue muerto a bayonetazos [...] a su cadáver, después de castrarlo y de cortarle una oreja, le quitaron la piel de los dos costillares para hacer maneas (282).

Borda (el Coronel D. Facundo); es fusilado en Monte Grande (Tucumán), después de prisionero por Oribe, quien le hace cortar las orejas al cadáver y se las remite a la hija de Rozas (285).

El uso pecuario del cuerpo enemigo y la apropiación de sus partes como trofeo de guerra, junto con la castración y la preferencia por el degüello como método de ejecución, colocan a las denuncias de "Tablas de sangre” en un diálogo sordo con el gran texto secreto del antirrosismo: El matadero. Porque, como en el cuento que no vería la luz hasta 1872, la violencia que Rosas ejerce sobre el cuerpo de sus enemigos deniega para ellos el estatuto de humanidad, conduciéndolos hacia una zona de indistinción con lo animal que, en palabras de Gabriel Giorgi, se concreta en la "transformación de un cuerpo en carne" (2014: 129). Devenidos en carne, en carne animal, los cuerpos enemigos del rosismo que Rivera Indarte y Echeverría representan pierden, junto con su humanidad, las garantías legales y morales que deberían proteger dicha condición y quedan entregados al ejercicio de la violencia del terror despótico. Pero si en El matadero la muerte animal alude por analogía a los crímenes de Rosas y el joven unitario consigue eludirla porque su ofuscación termina antes con su vida, en "Tablas de sangre”, en cambio, las víctimas enumeradas no corren igual suerte. De este modo, aunque en ambos textos se denuncian las violencias del régimen a través de la sobreabundancia de sangre, en el texto de Echeverría ésta provendrá de un cuerpo humano únicamente en dos episodios: cuando el lazo del toro decapite por accidente a un niño y cuando el unitario se desangre por la exacerbación de su propia rabia; en ninguno de los casos, en sentido estricto, intervendrán los cuchillos de la Mazorca, empleados 
únicamente en el degüello del ganado. Por el contrario, en el texto de Rivera Indarte, cuando se acuse a los hombres de Rosas de "lamer el cuchillo ensangrentado" (1853:280) o se narre una escena en la que Manuela Rosas roce las manos ensangrentadas de un asesino al compartir el mate, la sangre aludida será siempre sangre humana vertida por el poder despótico.

Redundar en denuncias y descripciones que hagan de la Buenos Aires de Rosas una ciudad bañada en sangre, del gobierno de Rosas un gobierno sanguinario, de la época de Rosas una época sangrienta, es un medio privilegiado por "Tablas de sangre" para evidenciar el modo en que el terror político violenta los cuerpos a los que somete. Desde el título mismo que escoge, Rivera Indarte encontrará en la alusión a la sangre derramada un modo de condensar los crímenes que denuncia, de darles, casi literalmente, espesor y color.

Pero "Tablas de sangre" registra también otro tipo de violencia sobre los cuerpos: la simbólica. La cinta punzó, por caso, es un tipo de marca que, en lugar de empujar el cuerpo enemigo hacia la animalidad, lo incluye de manera obligada en el entramado de prácticas y símbolos de la cultura federal. El luto impuesto a todos los habitantes de Buenos Aires tras la muerte de Encarnación Ezcurra, por su parte, no sólo desbarata la diferencia entre lo público y lo privado, haciendo de un asunto familiar un tema de Estado, sino que además sugiere el quiebre de otro límite: el que divide la soberanía política de la religiosa. Según Rivera Indarte, la primera obligación del luto impuesto por la muerte de Encarnación consiste, de hecho, en "encomendarla a Dios Nuestro Señor en nuestras diarias oraciones" (1853: 292): hasta las plegarias de los fieles quedan así bajo arbitrio de Rosas.

Ese desajuste entre lo sagrado y lo profano tiene múltiples caras: al culto a la imagen de Rosas se corresponde el gesto iconoclasta con que se ultima el destino de Dupuy, porteño acusado de traidor ("su cadáver, ridículamente ataviado, fue colgado en lugar de una de las estatuas de Judas" [1853: 291]); al luto impuesto por Encarnación se corresponde la prohibición de llevar luto o de dar a sus muertos cristiana sepultura que pesa sobre los deudos de enemigos políticos. Lo profano vuelto sagrado, lo sagrado profanado, las prácticas religiosas privadas confundidas con las públicas: una vez más Rivera Indarte dibuja para el ejercicio del poder soberano de Rosas una zona de indistinción.

Las alusiones al luto (el impuesto, el prohibido), como las sobre abundantes menciones de la sangre derramada, incorporan a "Tablas de sangre" no sólo una atrocidad más a la lista de atrocidades denunciadas, sino también un testimonio significativo de la maquinaria de terror y caos que representa el régimen rosista. Como derramar sangre enemiga, como regodearse en el derramamiento de sangre y hacer de él un espectáculo, impartir o abolir derechos al duelo, al llanto, a los ritos mortuorios, es otra forma de evidenciar que el poder soberano de Rosas no reconoce límites.

No obstante, y, una vez más, a diferencia de las largas parrafadas de razones, censuras y referencias eruditas que componen otros de sus textos, las denuncias efectuadas por "Tablas de sangre" no juegan su capital propagandístico a la persuasión razonada, pero tampoco a la mera descripción informativa. Por el contrario, parecen apuntar a un efecto de lectura que Rivera Indarte se permite explicitar: el horror.Si el concepto de terror que se aplica al régimen de Rosas implica el miedo reverencial sobre el que se funda el poder del déspota, la noción de horror involucra, además de miedo, aversión y espanto. Aversión frente a la forma humana desbaratada, frente al cuerpo despojado de forma y reducido a su mera carnalidad, frente a las prácticas entre sanguinarias y bufonescas con que se recubren y espectacularizan los crímenes del rosismo. Espanto frente al quiebre de los límites, frente a las leyes violentadas, frente a la religión y la moral corrompidas, frente al abandono absoluto de las garantías que resguardan la vida del hombre, sus libertades individuales y su integridad física. De ahí que horror, horroroso, horrible, horriblemente, en sus variantes de género y número, sean algunos de los términos que escanden el tono austero y neutro que predomina en "Tablas de sangre", aportando matices de valoración subjetiva. Más aún, de ahí que la nota al pie aclaratoria que inaugura el texto adelante un calificativo que recae sobre todos los episodios que se denunciarán a continuación: "lo que se quiere mostrar es el sacrificio de esas personas y la verdad de los hechos. ¿Ni cómo tampoco ser tan exacto á cuarenta leguas de distancia del teatro sangriento de estos horrorosos sucesos?” (1853: 275, la cursiva es mía). 
Con llamativa prolijidad, "Tablas de sangre” repite, incluso con la intermediación de los años y del cambio de bando, la misma lógica que se percibía en los versos de juventud de Rivera Indarte, cuando era un poeta federal escandalizado por el salvajismo unitario: frente a la sangre y el luto esparcidos por la violencia de las luchas intestinas, parece resonar una misma exclamación: "iqué horror!"

Sin embargo, la consecución de degüellos, desmembramientos, torturas y vejaciones denunciados no completan la imagen de Rosas que "Tablas de sangre” ofrece. Ese horror de carácter público que sus sucesivas entradas denuncian, se completa con la serie privada de aberraciones, muchas de las cuales no son sino tópicos muy recurridos de la literatura antirrosista. En efecto, el Rosas de Rivera Indarte no sólo es un bárbaro, un asesino, un sacrílego, un déspota que quiebra el orden social y pervierte sus reglas: también es un mal hijo que humilla a sus padres, y un padre incestuoso que transforma a Manuelita en su "manceba" (1853: 297). Del tono neutro del diccionario a los desbordes, del cálculo a la desmesura y -como el poder soberano de Rosasde la disputa pública y política a las escenas miserables de la vida privada: la estrategia retórica de "Tablas de sangre" también conlleva la transgresión de los límites. Con inexplicable soltura y exagerado detalle, casi como si hubiera recibido, al igual que Anastasio el Chileno, la visita de "un duende que ha venido / y que estuvo en lo de Rosas" (Ascasubi 1955: 200), Rivera Indarte se entromete, para construir una imagen global del horror que Rosas encarna, en la casa del tirano, en sus tratos familiares, en su alcoba. Elige, por lo tanto, no obviar la chismografía ya circulante en cartas, periódicos y panfletos de los exiliados, e incorporar esos minuciosos relatos de la vida privada, aun cuando podrían hacer sospechoso de ficción o de falacia a un texto que se pretende exacto y documental. Elige, en otras palabras, profundizar la difamación de Rosas, acentuar la construcción de su reputación de infame, aun cuando implique quebrar su propia estrategia retórica y propagandística. Como si tampoco debiera ser contemplativo de los límites impuestos por sus propios modos de enunciación el ejercicio de una escritura en permanente pie de guerra.

\section{BIBLIOGRAFÍA}

Agamben, Giorgio (2006). Homo Sacer. El poder soberano y la nuda vida, Valencia, Pre-Textos.

Angelis, Pedro de (2009). "El Comodoro Purvis juzgado por la razón, la opinión pública, y los escritores del derecho de gentes (Conclusión)”, en Paula Ruggieri (Comp.), Archivo americano y espiritu de la prensa del mundo. Primera serie 1843-1847, Buenos Aires, Biblioteca Nacional.

Ansolabhere, Pablo. (2012). "Escrituras de la barbarie", en Adriana Amante (Dir.), Sarmiento. Historia critica de la literatura argentina, vol. IV, pp. 293-313,Buenos Aires, Emecé.

Area, Leila (2006). "Proferir lo inaudito: 'Tablas de sangre', de José Rivera Indarte”, en The Colorado Review of HispanicStudies, vol. 4, pp. 189-204.

Ascasubi, Hilario (1955), "Isidora la federala y mashorquere”, en Jorge Luis Borges y Adolfo Bioy Casares (Eds.),Poesía gauchesca, México, Fondo de Cultura Económica.

Bataille, George (2010). El erotismo, Buenos Aires, Tusquets.

Echeverría, Esteban (2007). El Dogma Socialista y Otros Escritos, Buenos Aires, Terramar.

Echeverría, Esteban (1941a). “Tercera carta de Echeverría a Rivera Indarte”, en Alberto Palcos, Echeverría y la democracia argentina, Buenos Aires, El Ateneo.

Echeverría, Esteban (1941b). "Segunda carta de Echeverría a Rivera Indarte”, en Alberto Palcos, Echeverría y la democracia argentina, Buenos Aires, El Ateneo.

Giorgi, Gabriel (2014). Formas comunes. Animalidad, cultura, biopolitica, Buenos Aires, Eterna Cadencia.

Kohan, Martín. (2006). "Las fronteras de la muerte”, en Alejandra Laera y Martín Kohan (Comps.), Las brújulas del extraviado. Para una lectura integral de Esteban Echeverria, pp. 171-203, Rosario, Beatriz Viterbo.

Lucero, Nicolás (1992). La máquina infernal. Apuntes sobre Rivera Indarte, Buenos Aires, Facultad de Filosofía y Letras. 
Montesquieu (2007). Del espiritu de las leyes. Buenos Aires, Losada.

Myers, Jorge (2011). Orden y virtud. El discurso republicano en el régimen rosista. Bernal, Universidad Nacional de Quilmes.

Palcos, Alberto (1941). Echeverria y la democracia argentina, Buenos Aires, El Ateneo.

Robin, Cary (2004). Fear. The history of a political idea, Nueva York, Oxford University Press.

Rojas, Ricardo (1948). Historia de la literatura argentina. Vol. II, Buenos Aires, Losada.

Rivera Indarte, José (1853). Rosas y sus opositores, Buenos Aires, Imprenta de Mayo.

Rivera Indarte, José (1941a). “Tercera carta de Rivera Indarte a Echeverría”, en Alberto Palcos, Echeverría y la democracia argentina, Buenos Aires, El Ateneo.

Rivera Indarte, José (1941b). "Fiestas mayas", en Alberto Palcos, Echeverría y la democracia argentina, Buenos Aires, El Ateneo.

Rivera Indarte, José (1941c). "Respuesta de Rivera Indarta a 'Un Oriental”, en Alberto Palcos, Echeverría y la democracia argentina, Buenos Aires, El Ateneo.

Saldías, Adolfo (1978). Historia de la Confederación Argentina, Buenos Aires, Eudeba.

Sarmiento, Domingo (2006). Facundo, Buenos Aires, Colihue.

Schvartzman, Julio. (1996). "Facundo y la lucha por el sentido", en Microcriticas, Buenos Aires, Biblos.

\section{Notas}

1 Según Jorge Myers, la literatura de Rivera Indarte transita, en el plazo de dos años, por las páginas de El Imparcial, La Lanza Federal y el Diario de Anuarios y Publicaciones Oficiales, hasta que llega a convertirse, de manera efímera, en director de La Gaceta Mercantil (2011: 44).

2 Alberto Palcos ofrece en Echeverria y la democracia argentina (1941) una revisión documentada de los antecedentes, emergencia y trayectoria de la Asociación de Mayo, así como también del intercambio polémico que mantuvieron Echeverría y Rivera Indarte en 1844. Las citas que, en lo sucesivo, se ofrecen al respecto han sido extraídas del apéndice documental de dicho volumen.

3 La polémica entre Echeverría y Rivera Indarte a propósito de lo ocurrido en las fiestas mayas de 1844 comienza con una crónica aparecida en El Nacional el 27 de mayo, en la cual se hace alusión a las "distinciones especiales" (Rivera Indarte 1941b: 162-163) recibidas por la composición de Domínguez, sin señalar en modo alguno un resultado semejante luego de la lectura del texto de Echeverría. Aunque median tibias disculpas en carta privada de Rivera Indarte a Echeverría, el 31 de mayo la querella recrudecerá cuando El Nacional publique dos textos que aluden al tema: una nota firmada por "Un Oriental", que recrimina a Rivera Indarte el haber pasado por alto el clamor del público ante el poema de Echeverría, y una respuesta del propio director del diario, verdadero punto de inflexión en la polémica, en la cual, además de someras justificaciones y elogios de tono general, Rivera Indarte acicatea a su rival con un par de frases insidiosas y calculadas que sugerirán, por un lado, que su aporte más original a la literatura local fue "haber inoculado en nuestro país la poesía nueva" (1941c: 165), es decir, haber oficiado de mero importador del romanticismo, y, por el otro, que su prédica antirrosista es reciente ("con la composición suya en honor de Mayo [...] [Echeverría] ha comenzado dignamente su apostolado contra Rosas") (1941c: 166). El último ribete público del asunto, llegaría bajo la forma de una carta de Echeverría dirigida al "Sr. Editor del Nacional" y publicada el $1^{\circ}$ de julio en El Constitucional. A partir de entonces, el intercambio epistolar trazará un incesante aumento de las hostilidades, coronado por una extensa y lapidaria carta de Echeverría, hasta que, según señala Palcos “[a]migos comunes logran poner fin a la controversia” (1941: 104).

4 "Vd., Señor Indarte, tan "jovencito" metiéndose a ridiculizar a la Joven Generación, que alzó la bandera de la Democracia, cuando V. se alistaba en la Mashorca" (Echeverría 1941a: 179).

5 "Entremos ahora a lo más lindo: á ese apostolado sublime de abnegación y de patriotismo que V. vocifera tanto, á ese apostolado que empezó V. el año 35 alistándose en la 'mashorca' y que solemnizó con un himno al Restaurador”( Echeverría 1941a: 180).

6 Como La Gaceta Mercantil, bajo la dirección de Nicolás Mariño, y el Archivo Americano, dirigido por Pedro De Angelis, Echeverría utilizará la breve instancia de Rivera Indarte en la cárcel como una herramienta de descrédito: "[c]uando yo servía la buena causa Ud. estaba..... no sé dónde" (Echeverría 1941b: 169). Rivera Indarte, desde luego, recogerá el guante, contestando en la misma línea que cuando las acusaciones llegaban desde la otra orilla del Río de la Plata, es decir, dotando de épica patriótica una circunstancia que, en la perspectiva de sus detractores, no la tuvo en absoluto: 
“yo estaba...... dígalo Ud..... en la cárcel; — pero por patriota” (Rivera Indarte 1941a: 171). La explicación que sugiere el bando contrario, y a la que, sin dudas, Echeverría trata de dar crédito con sus sugerentes puntos suspensivos, es bien distinta: el furor repentino de Rivera Indarte contra Rosas debe explicarse como un modo de "vengarse así de la prisión que éste [...] le hizo sufrir por haberse robado la Corona de Nuestra Señora de Mercedes, del Templo de esta advocación en esta ciudad, y por otros robos y maldades" (DeAngelis 2009: 209).

7 Un temprano ejemplo de esa salida de tono se encuentra en la entrada destinada al mes de abril de 1835, en la cual se hace referencia a la segunda llegada de Rosas a la gobernación de Buenos Aires y se utilizan adjetivos como "ominoso" para referir al renovado régimen, y adverbios como "horriblemente" (Rivera Indarte 1853: 276) para hablar del tratamiento que comenzaron a recibir desde ese momento los opositores. Asimismo, la entrada dedicada a fray Félix Aldao será una de las más extensas y también una de las más cargadas de calificativos. En ella se narrarán varios episodios vinculados con este "teniente del degollador Rozas" (Rivera Indarte 1853: 278) y se citarán testimonios que refieran, desde una óptica cruda y parcial, los crímenes denunciados. A lo largo del texto, sin embargo, la adjetivación será austera y no abundarán los calificativos que denoten el posicionamiento faccioso del autor, con la única excepción de los que acompañen a la mención de Rosas. Si los términos descomedidos son excepcionales en "Tablas de sangre”, en el caso de las alusiones a Rosas la regla se invierte: lo excepcionales que se lo mencione sin la compañía de epítetos tales como "degollador" o "tirano". No obstante, estos términos parecen haberse adherido al nombre propio del enemigo político en todas las manifestaciones literarias del antirrosismo, reduciendo así parcialmente su carga subjetiva y tornándose casi un lugar común de la escritura facciosa.

8 Saldías se ocupa en detalle de registrar algunas de las más peculiares instancias de esta polémica, contrastando las efemérides publicadas en El Nacional (luego entradas de "Tablas de sangre"), con las desmentidas que recibían por parte de La Gaceta Mercantil (1978: 343-345).

9 Rigidez, no obstante, que sólo se observa a rajatabla en la agrupación de entradas según la letra inicial de cada palabra, y se ignora frecuentemente en las letras subsiguientes. Así, por citar sólo un ejemplo, entre las entradas de Don Avelino Viamonty la de Don Cirilo Viamonte, aparece la del coronel Videla (Rivera Indarte 1853: 313).

10 Aun sin la necesidad de contrastar los hechos y los números que "Tablas de sangre" denuncia, su balance final admitiría cuestionamientos. Por ejemplo, las cifras de muertes por el rosismo que Rivera Indarte ofrece considera a los propios soldados de Rosas muertos en combate como víctimas de la tiranía. 